\title{
An Online-Based Edu-Escape Room: A Comparison Study of a Multidimensional Domain of PSTs with Flipped Sustainability-STEM Contents
}

\author{
Félix Yllana-Prieto (D), Jin Su Jeong * (D) and David González-Gómez (D) \\ Departamento de Didáctica de las Ciencias Experimentales y Matemáticas, Universidad de Extremadura, \\ 10003 Cáceres, Spain; feyllanap@unex.es (F.Y.-P.); dggomez@unex.es (D.G.-G.) \\ * Correspondence: jin@unex.es
}

Citation: Yllana-Prieto, F.; Jeong, J.S.; González-Gómez, D. An Online-Based Edu-Escape Room: A Comparison Study of a Multidimensional Domain of PSTs with Flipped SustainabilitySTEM Contents. Sustainability 2021

13, 1032. https://doi.org/10.3390/ su13031032

Academic Editor: Marc A. Rosen

Received: 26 December 2020

Accepted: 16 January 2021

Published: 20 January 202

Publisher's Note: MDPI stays neutral with regard to jurisdictional claims in published maps and institutional affiliations.

Copyright: (c) 2021 by the authors. Licensee MDPI, Basel, Switzerland. This article is an open access article distributed under the terms and conditions of the Creative Commons Attribution (CC BY) license (https:// creativecommons.org/licenses/by/ $4.0 /)$

\begin{abstract}
The use of active and flipped methodologies has increased in recent years. Here, gamification uses typical elements of a game in different contexts, including that of education. Specifically, Escape Room games used as educational tools have potential for teaching-learning, and they can be beneficial because they can improve students' motivation and emotions toward learning. This is particularly valuable in science, technology, engineering and mathematics (STEM) courses, where the cognitive factor and multidimensional domain are closely connected. This research presents an online-based Edu-Escape Room with science and sustainability contents as an educative tool in a STEM course. With the intervention proposed, we analyze how this tool influences the multidimensional domain (attitudes, self-efficacy and emotions) of pre-service teachers (PSTs). According to attitude and self-efficacy analysis, it is observed that most of the items analyzed show an increase in self-efficacy and more positive attitudes after the intervention. In particular, Question 11 (Q11) indicates a significant difference. Concerning the results for emotion, the positive emotions "joy", "satisfaction" and "fun" are significantly increased after the intervention. However, the negative emotions "nervousness", "frustration" and "concern" also increase, partly due to the game characteristics. The proposed activity had a medium effect on items with significant differences except for the emotion "frustration", where the intervention had a large effect according to effect size (ES) analysis. According to the principal component analysis (PCA), the attitudes, self-efficacy and emotions of the PSTs are positively correlated, and the influence of the proposed activity shows a significant improvement in these variables. Finally, the structural equation modeling partial least squares (SEM-PLS) analysis showed the effects that the instruction has on the PSTs' emotions and also that they had a significant effect on the positive attitudes towards and self-efficacy in science. Therefore, there are multiple benefits in the multidimensional domain of PSTs of having implemented the proposed online-based Edu-Escape Room.
\end{abstract}

Keywords: Escape Room; gamification; attitude/auto-efficiency; emotion; PST; STEM education; flipped classroom

\section{Introduction}

With the popular increase in active and flipped learning methodologies in the classroom, the use of games can help to support students' satisfaction, grades, collaboration and motivation for learning [1-3]. Thus, game-based education has provided the opportunity for an interdisciplinary approach that takes into consideration how to promote a realistic environment with the aim of achieving a better student experience [2,3]. In this context, Deterding [4] indicated that gamification normally uses the typical elements and techniques of games in different contexts, such as those of business or education. In particular, in university education, various studies show successful practices through the use of gamification [5-7]. They even reveal that the students who participate tend to achieve better academic performance, motivation and attitudes towards their courses [5-7]. In a 
context of gamification, an Escape Room, a didactic application, is a live-action game in which participants can discover clues, solve puzzles and perform tasks in one or more rooms in order to reach a specific goal that will allow them to leave the room in a limited amount of time $[2,8,9]$. Thus, Nicholson [10] points out the importance of connecting the teaching-learning activities into the history and context of the Escape Room so that the students can be involved in the narrative process and can then be inspired to connect with real problems and develop an intrinsic motivation to learn and explore [11,12]. However, the use of gamification and Escape Rooms in higher education is still in a premature phase; they are scarce tools, although they have potentials for teaching-learning. In these situations, with higher demands and challenges, the Escape Room is a gamification tool that can be used in science, technology, engineering and mathematics (STEM) courses along with the students' multidimensional domains [13,14].

Along with gamification in active and flipped methodologies, STEM has received increasing attention in recent years for its ability to provide proper preparation for students $[14,15]$. The UN decade of education for sustainability development (DESD) has described current STEM education situations [16,17] that can promote communal awareness of values and increase life-long training [16,18-20]. STEM education proposes the integration of various scientific disciplines as a cohesive entity, the teaching of which is integrated and coordinated so it can be used for problem-solving in everyday situations [21]. In fact, Wiswall et al. [22] suggested that students who participate in programs and activities focused on STEM courses obtain better grades in STEM subjects than those who do not participate. Moreover, it was observed that students participating in these STEM programs choose STEM degrees more frequently than students who did not participate. However, despite the implementation of STEM methodologies being useful in promoting scientific literacy for students, disinterest is one of the main causes of a negative attitude towards science [23]. According to Vázquez and Manassero [24], students begin to show disinterest in scientific disciplines at an early age, initiating a negative image of science in general and a subsequent abandonment of the idea of choosing a STEM career. In addressing this challenge, it is important to take into account the preferences of students in order to generate interest in scientific disciplines from an early age since these preferences and interests persist into adulthood and can facilitate the choice of STEM careers [25]. Therefore, it is important to increase the positive affective domain of students in STEM courses, which can be done through gamification and Escape Rooms in active and flipped methodologies.

In the context of gamification and Escape Rooms and with the use of active and flipped methodologies, student satisfaction, grades, collaboration and motivation have been increased in the classroom [2,3]. This indicates that different types of positive emotions are promoted and highlights the importance of motivation, interest, academic self-concept, cognitive activity, learning achievement and fun [26]. Here, students experience the proposed enigmas, as well as their usefulness in promoting collaboration and teamwork in an educational environment [26,27]. In this context, emotions in science teaching-learning play a fundamental role because they are closely connected with the cognitive factor. Some authors $[28,29]$ have described the dependence between the rational and the emotional domain and argued that there is an increasingly clear relationship between the two domains [30]. Encouraging the presence of positive emotions in students during the study of a subject favors learning, while the generation of negative emotions limits it [28,30]. However, some studies [31,32] reveal that these types of activities also generate emotions such as stress and frustration, especially in items or tests of greater difficulty. The emotional factor is also related with self-efficacy in the teaching-learning processes [27]. According to Bandura [33], teachers' self-efficacy refers to a teachers' individual awareness of their effectiveness, that is, the degree of their capacity to motivate students to higher levels of performance. Some studies [34,35] found a positive correlation between self-efficacy and academic success, such that a strong sense of self-efficacy predicts increased performance and success, which then become grounds for greater self-efficacy. In particular, Kazempour [36], in a study of future teachers, points out that understanding the negative 
experiences and difficulties with science for pre-service teachers (PSTs)allows one to better understand their low self-efficacy and negative attitude towards science teaching, as well as the interrelation between beliefs, self-efficacy and attitude towards science if lasting changes that lead to an improvement in their teaching practices are wanted [36-38]. In addition, PSTs' attitudes are important, influencing students' motivation to choose STEM careers and influencing cognitive-affective variables such as self-efficacy, attitudes, motivation and beliefs [37,38]. It is important to generate positive emotions in the teachers in training so that they feel competent and trained to teach STEM, since it depends on them to generate interest in STEM for future generations [39]. Therefore, it is necessary to have a specific study to have a balance the aforementioned as gamification application to improve PSTs' multidimensional domain in a flipped STEM course.

This research aims to analyze the effects of the multidimensional domain of PSTs produced by the online-based Edu-Escape Room used as an educative tool to teach content related to the Universe in a course at the Primary Education degree of the University of Extremadura (Spain). This study focuses on the design, development and subsequent analysis of the online-based Edu-Escape Room. Specifically, we analyzed the intervention affects the attitudes, self-efficacy and emotions of the PSTs. Here, an effect size (ES) analysis was used to measure the magnitude of the activity effect, and it was checked whether they followed any distribution pattern. To complete the study, a principal component analysis (PCA) and the structural equation modeling, partial least squares (SEM-PLS), were conducted with the objective to interpret the variables with significant differences and determine how these variables correlated.

\section{Materials and Methods}

In this research, an online-based Edu-Escape Room of contents related to the Universe applied into a flipped class as a teaching tool is analyzed. A comparative study was carried out to analyze attitude, self-efficacy and emotion of PSTs as a multidimensional domain through a questionnaire given before and after the proposed intervention (preand post-test).

\subsection{Sample and Instruments}

The study was conducted with 42 PSTs enrolled in a science course called "Knowledge of the natural environment in primary education", which is taught using a flippedclassroom teaching methodology. The course was taught in the senior course of the Primary Education degree (University of Extremadura, Cáceres, Spain) during the first semester of the 2020/2021 course. No constraints were imposed, and the PSTs freely chose whether they wanted to participate in this research.

The PSTs who participated in the study had a mean age of 23 years old, with $90 \%$ in the 15-20 age range and the remaining 10\% equally distributed between ages 26-30 and over 40. The PSTs had a mean university entrance grade of 7.46 (scale 1 to 10). It is important to note that the PSTs enrolled in this program had mostly studied Humanities or Social Sciences during their pre-university education (69.05\% of the participants). Figure 1 provides more complete demographic information about the sample.

Regarding the instruments used in the study, the collection of data was carried out using a questionnaire with two sections in order to measure the different variables studied: attitude and self-efficacy, and emotions towards science and the proposed intervention. This questionnaire was based on quantitative items that could be measured by a fivepoint Likert scale from 1 to 5 . There were a total of 34 items in the questionnaire, i.e., 24 items regarding attitude (Q1 to Q7 correspond to AF_1 to AF_7) and self-efficacy (Q8 to Q24 correspond to ATT_1 to ATT_17) and 10 items (5 positive as E_1 to E_5 and 5 negative emotions as E_6 to E_10) regarding emotions towards science and the intervention proposed (see Table 1). 


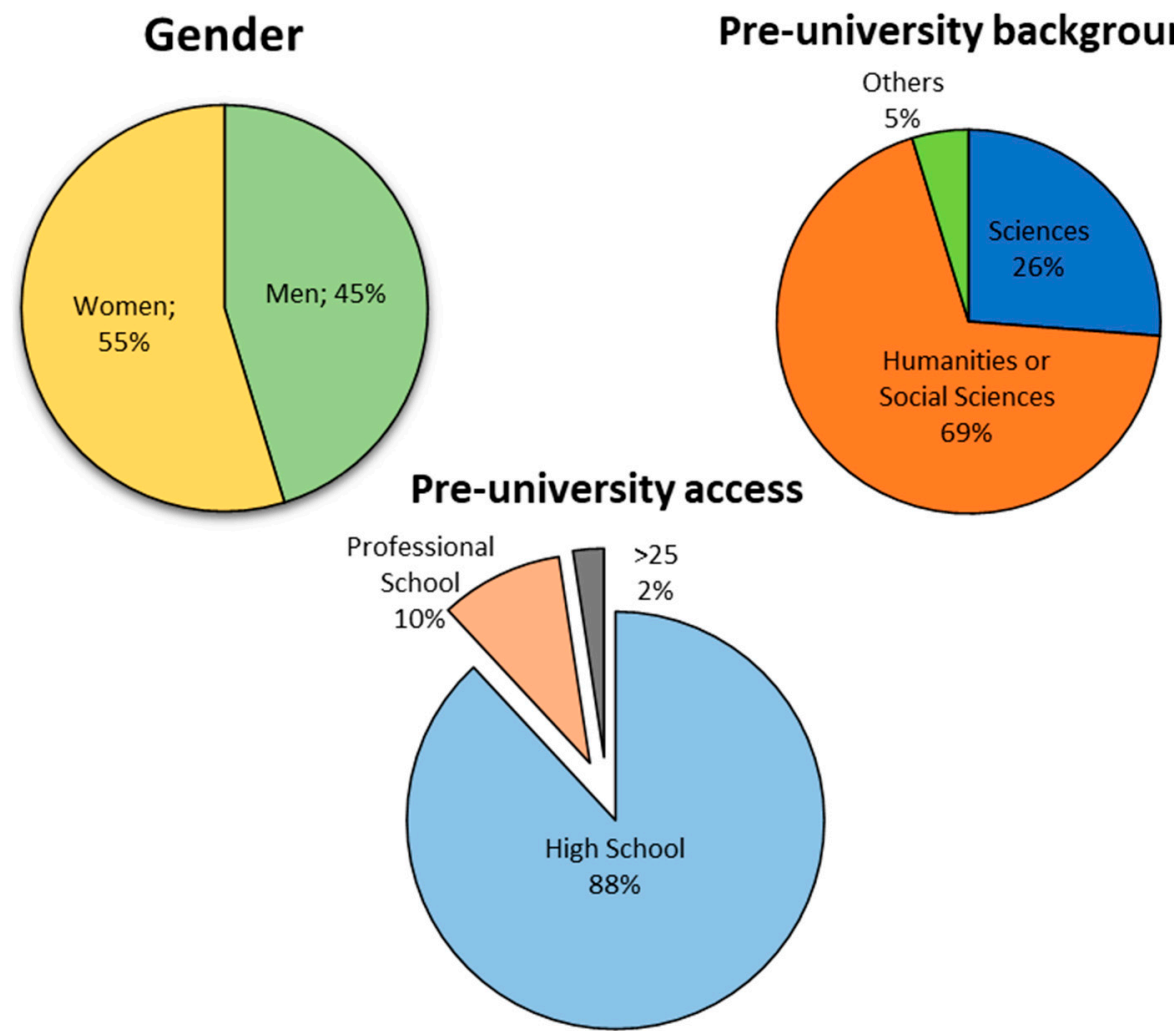

Figure 1. Demographic information about gender, pre-university background and pre-university access of the sample.

First, a 24-item questionnaire was used to measure the attitude and self-efficacy towards science and the proposed intervention, online-based Edu-Escape Room, of the participants. Attitudes towards science and intervention proposed by PSTs were analyzed and measured using the instrument designed by Schruba [40]. Here, the PSTs' attitudes were assessed by considering their favorable or unfavorable feelings towards science and the intervention proposed. Self-efficacy about science and the intervention proposed were measured by various items adapted from the science teaching efficacy belief instrumentpreservice (STEBI-B) [41], developed to analyze the self-efficacy of instructors with regard to science and science teaching. The validity and reliability of both questionnaires (attitudes and self-efficacy) were tested and confirmed in various studies [42-44]. For both attitudes and self-efficacy towards science and the intervention proposed, a five-point Likert scale was applied, in which the lowest value was "Strongly Agree" and the highest value was "Strongly Disagreed" before and after intervention implementation (pre- and post-test).

Then, a 10-item questionnaire was used to measure the emotions of the PSTs regarding the expectation of making an online-based Edu-Escape Room about the Universe, along with other science topics, before and after its development (pre- and post-test). This questionnaire has been validated in various research published $[39,45,46]$. Here, the PSTs were questioned about the intensity of 10 emotions: 5 positive emotions were joy, confidence, satisfaction, enthusiasm and fun, and 5 negative emotions were concern, frustration, uncertainty, nervousness and boredom. They were selected from the emotions that the PSTs could experience in the face of a teaching-learning process according to certain classifications as positive and negative emotion groups of Bisquerra [47]. Specifically, these emotions were quantified from the value of 1 to 5 (a five-point Likert scale), corresponding to the value 1 to never have felt that emotion and the value 5 to have felt it very intensely. The value 3 is the intermediate value, and values 2 and 4 determine "a little" and "sufficient", respectively. 
Table 1. Questionnaire description about attitude, self-efficacy and emotions. The nomenclature between parentheses refers to the type of item (ATT: attitude, AF: self-efficacy and E: emotion item).

Questionnaire

\section{Attitude and Self-Efficacy Items}

Q1. I understand scientific concepts well enough to teach science at lower educational levels. (AF_1)

Q2. I am typically able to answer students' science questions. (AF_2)

Q3. Even though I try very hard, I do not teach science as well as I teach most subjects. (AF_3)

Q4. I believe I have the required skills to teach scientific content. (AF_4)

Q5. I will be very effective in monitoring science experiments. (AF_5)

Q6. Science subjects have always been my favorites. (AF_6)

Q7. Science is useful for solving problems. (AF_7)

Q8. Doing laboratory activities is fun. (ATT_1)

Q9. It is important to know about science to get a good job. (ATT_2)

Q10. I know the steps necessary to teach science concepts effectively. (ATT_3)

Q11. I like the challenges of scientific activities. (ATT_4)

Q12. I am comfortable in science class. (ATT_5)

Q13. Science is easy for me. (ATT_6)

Q14. The inadequacy of a student's science background can be overcome by appropriate teaching. (ATT_7)

Q15. I find it difficult to explain a science concept to students. (ATT_8)

Q16. No matter how hard I try, I cannot learn science. (ATT_9)

Q17. When I hear the word "science", I feel a sense of inconvenience. (ATT_10)

Q18. I feel that I am not able to teach science properly. (ATT_11)

Q19. I often think, "I cannot do this", when a science assignment seems hard. (ATT_12)

Q20. I am interested in the Universe as a science subject. (ATT_13)

Q21. I find the mathematical concepts of density, weight, mass, volume, distance, radius and diameter useful. (ATT_14)

Q22. I am interested in gamification as a science teaching methodology. (ATT_15)

Q23. I am interested in Escape Rooms as a science teaching tool. (ATT_16)

Q24. I am interested in making an Escape Room about the Universe as a science subject. (ATT_17)

\begin{tabular}{cc}
\hline & Emotion Items \\
\hline Positive emotion & Negative emotion \\
\hline Joy (E_1) & Nervousness (E_6) \\
Satisfaction (E_2) & Frustration (E_7) \\
Enthusiasm (E_3) & Uncertainty (E_8) \\
Fun (E_4) & Concern (E_9) \\
Confidence (E_5) & Boredom (E_10) \\
\hline
\end{tabular}

\subsection{Course Context and Procedure}

The participants, PSTs, were in the same group, studying the subject in which the intervention was implemented. The course is called "Knowledge of the natural environment in primary education" and is organized into three different blocks of contents. The course contents comprised current challenges in science education and learning to teach science in primary school with different strategies and contents at the primary education stage- such as the importance of science for sustainable development and environmental issues and the role that science has to prevent it-through projects on the curriculum of the knowledge of the natural environment in primary education and resources and didactic materials. This course has a total of $150 \mathrm{~h}$ ( 6 credits). Table 2 provides specific information in the context of the course teaching plan.

Before applying the intervention proposed, the online-based Edu-Escape Room on content related to the Universe, the 42 PSTs answered the questionnaire about attitudes, self-efficacy and emotions towards science and the intervention (pre-test). Due to the COVID-19 outbreak, the activity was made in an online session through Zoom, in which the PSTs connected to a virtual meeting organized by the instructors. In this meeting by videoconference, a synchronous follow-up of the activities completed by the PSTs was developed, clues were provided and doubts were resolved. Therefore, the studentinstructor interaction was closely interchanged during the activity despite not being in a 
face-to-face environment. In the context of the online-based intervention proposed, the PSTs completed the Escape Room individually through their computer, tablet or mobile from their respective homes. Finally, as soon as they finished this activity session, they were dedicated to answering the questionnaire that analyzed attitudes, self-efficacy and emotions towards science and intervention proposed after completing the online-based Edu-Escape Room (post-test). All interactive educational materials were provided to the PSTs through the online University platform, Moodle, for a proper teaching and learning process.

Table 2. Course description about teaching plan proposed.

\begin{tabular}{|c|c|c|}
\hline \multicolumn{3}{|c|}{ Knowledge of the Natural Environment in Primary Education } \\
\hline $\begin{array}{l}\text { General course } \\
\text { contents }\end{array}$ & \multicolumn{2}{|c|}{$\begin{array}{l}\text { Study of the natural environment, problem-solving and practical work in the classroom and laboratory, } \\
\text { cultural value of science, didactic projection of the relationship between science, technology and society, } \\
\text { didactic units in the classroom, resources and didactic materials, interdisciplinarity in the } \\
\text { teaching/learning of science, and special educational needs in science teaching/learning. }\end{array}$} \\
\hline \multirow{4}{*}{ Course structure } & Topics & Contents \\
\hline & T1. Current challenges in science education. & $\begin{array}{l}\text { Didactic projection of science, technology and } \\
\text { society. Scientific education and transversal topics. } \\
\text { Interdisciplinarity in science teaching-learning. }\end{array}$ \\
\hline & $\begin{array}{l}\text { T2. Learning to teach science in primary school } \\
\text { through different strategies. }\end{array}$ & $\begin{array}{l}\text { School research, natural environment trips, } \\
\text { problem-solving, practical work and project work. }\end{array}$ \\
\hline & $\begin{array}{l}\text { T3. Contents of science education for the primary } \\
\text { education stage. Projects on the curriculum of the } \\
\text { knowledge of the natural environment in primary } \\
\text { education. Resources and didactic materials. }\end{array}$ & $\begin{array}{l}\text { Teaching-learning activities: the environment and } \\
\text { its conservation, the diversity of living beings, } \\
\text { health and personal development, matter and } \\
\text { energy, sources of renewable energies, technology, } \\
\text { sustainable education, environmental education } \\
\text { and objects, and machines. }\end{array}$ \\
\hline Course duration $(150 \mathrm{~h})$ & \multicolumn{2}{|c|}{ Practical activities $(15 \mathrm{~h})$} \\
\hline
\end{tabular}

To motivate and involve the PSTs to actively participate in this session, the rating of this activity was based on the speed with which the participants solved the onlinebased Edu-Escape Room. Furthermore, the instructors encouraged the interaction and involvement of participants through the online session and had an active role and constant attention to the PSTs' doubts and concerns.

\subsection{Online-Based Edu-Escape Room Design}

The online-based Edu-Escape Room designed deals with the contents related to the Universe; specifically, the theoretical contents of the activity are based on the solar system, the Sun and its role as a source of renewable energy for sustainable development. Other general concepts such as definitions of planets, asteroids, satellites, movements of planets, order in the solar system, density, perimeter, radius and diameter were also studied.

First, the concepts of "gamification" and "Escape Room" used as a teaching tool in the class were explained to the participants. Then, when this theoretical basis was explained and understood, the online-based Edu-Escape Room started as a class activity. It consisted of five assignments that the PSTs should solve during the online session using their computers and other devices individually (see Figure 2). The online-based Edu-Escape Room was designed in such a way that solving a challenge leading to the next task, and it was not possible to advance to the next test without having solved the previous ones. 


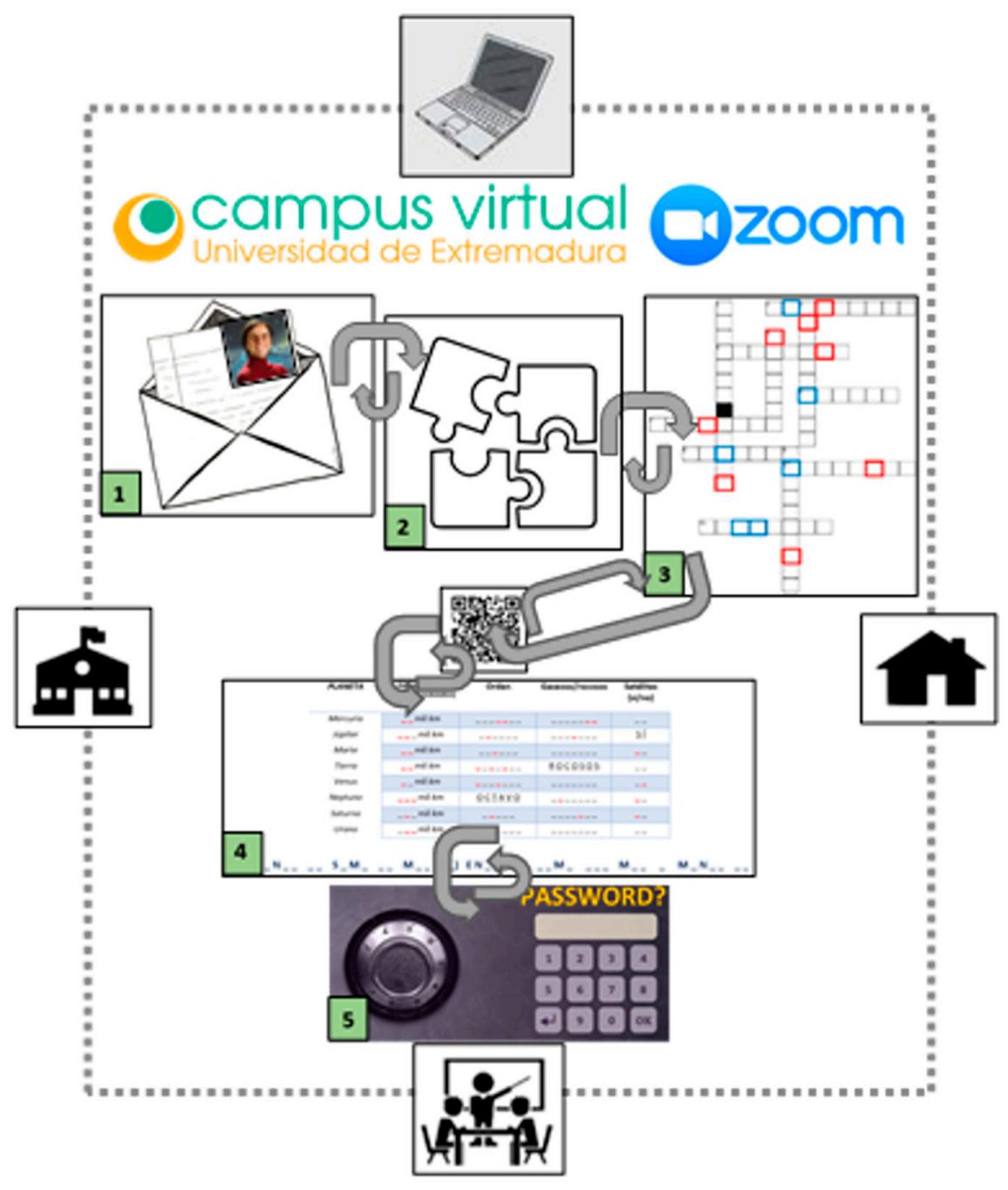

Figure 2. Challenges that the participants must solve to complete the online-based Edu-Escape Room.

One of the best-known scientists in the study of the Universe is Carl Sagan. As shown in Figure 2, in the context of the activity, he sent a letter to the participants through the university's online platform with all the instructions they must follow to complete the activity (1). This letter guides students to two links; the first to a digital lock (which they could not open because they did not know the password) and the second to a digital puzzle (2) that could be completed by dragging the pieces with the computer mouse. After solving this puzzle, the participants could read the question "What positions do the Sun, Earth and Moon have during the eclipse of the Moon?", and giving a correct solution to this question would unlock the next challenge on the platform. The next task was a crossword puzzle (3) about the general contents of the solar system. Some words in the crossword were marked and, by ordering them in a logical way, the participants already knew that they had to ask for a Quick Response (QR) code from the instructors in order to download the next challenge. The following task (4) consisted of the data about the planets of the solar system (composition, order, satellites and perimeter) that the PSTs should find out by searching in notes, books or on the Internet. Here, some of the words and numbers were marked, and if they were properly arranged, a mathematical operation with a three-digit number is obtained. This numerical combination should be input into the digital lock (5) to reach the final goal and complete the online-based Edu-Escape Room. 


\subsection{Data Analysis}

A descriptive analysis was firstly carried out due to its common use as the most appropriate way to characterize, describe and draw conclusions from the data of a sample [48,49]. To measure the reliability and validity of the questionnaires used in the study, Cronbach Alpha Coefficient was applied, demonstrating that the questionnaires used were reliable, as shown in Table 3.

Table 3. Cronbach Alpha test results.

\begin{tabular}{cc}
\hline \multicolumn{2}{c}{ Cronbach Alpha Test } \\
\hline Questionnaire & Value \\
\hline Attitudes and self-efficacy & $0.82^{*}$ \\
Emotions & $0.76^{*}$ \\
\hline
\end{tabular}

* Values above 0.7 confirm that the questionnaire used is adequate.

To reach plausible conclusions about the effects of the evaluated teaching tool, the homogeneity of the sample was tested. The Shapiro-Wilk normality test was performed to establish whether the data were normally distributed or not. As data were not normally distributed, non-parametric statistical tests were performed. Here, the Mann-Whitney test was used to establish the existence of significant differences between the values of the variables under study before and after the intervention. The ES was also calculated to measure the strength of the relationships between variables. Then, the PCA was calculated to reduce the dimensionality by projecting each data point onto only the first few principal components. In these cases, the statistical software SPSS (SPSS statistics 22.0) was used. Finally, the SEM-PLS analysis was conducted in order to assess the relationship between the variables studied in this research. For this analysis, the SmartPLS software was employed.

\section{Results and Discussion}

The data collected through the questionnaire were statistically analyzed to obtain plausible conclusions about the multidimensional domain of PSTs. Once the reliability of the questionnaires using the Cronbach Alpha Coefficient and the non-normality of the data using the Shapiro-Wilk test had been analyzed, the results were classified according to the different statistical tests (comparative analysis of means, ES test, PCA test and SEM-PLS analysis) carried out on each of the variables studied (attitudes, self-efficacy and emotions).

\subsection{Comparative Analysis of Survey Questionnaires}

In order to measure the effects of the online-based Edu-Escape Room proposed on the PSTs multidimensional domain, the answers given by the participants in the 24-item questionnaire about attitude and self-efficacy ( 7 and 17 items, respectively) were analyzed. Figure 3 shows the comparison of means (scale 1 to 5) of the 24 items about attitude and self-efficacy before and after implementing the online-based Edu-Escape Room (pre- and post-test). It should be noted that most of the items corresponded to issues related to positive attitude and high self-efficacy towards science; a score of 5 on the scale indicated a positive attitude or high self-efficacy. Only items Q15, Q16, Q17, Q18 and Q19 were associated with issues related to a negative attitude and low self-efficacy towards science, so a value of 5 on the scale corresponded to negative attitude or low self-efficacy towards science. Although there was a slight improvement in most items, statistically significant differences were observed only in Question 11 (Q11) "I like the challenges of scientific activities" ( $p$-value $=0.031$ ), where the mean changed from 3.74 to 4.16 before and after the intervention (difference of 0.42 points). 


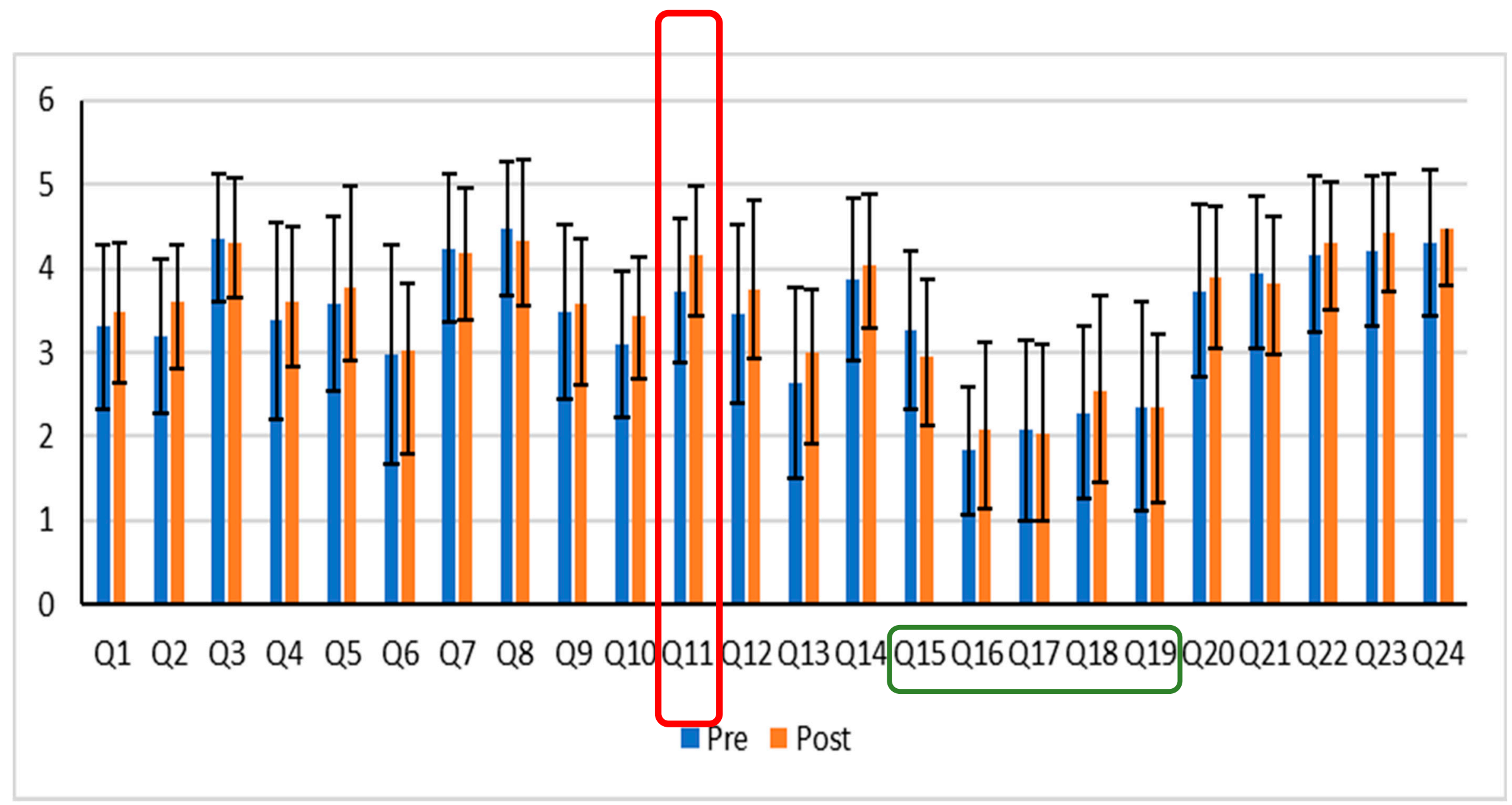

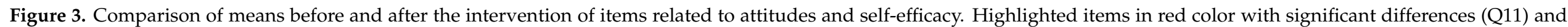
highlighted items in green color with negative attitudes and low self-efficacy towards science. 
Concerning the emotions felt by the PSTs before and after the intervention, there was an increase in all emotions, except for confidence after the intervention. It was observed that there were significant differences in 6 of 10 emotions analyzed: 3 positive emotions (joy, satisfaction, fun) and 3 negative emotions (nervousness, frustration and concern). Among the positive and negative emotions, enthusiasm and confidence, and uncertainty and boredom, respectively, the differences that were detected were not significant. Figure 4 shows a result on the comparison of means (scale 1 to 5 ) of these 6 emotions ( 3 positives and 3 negatives) in which significant differences had been detected before and after implementing the online-based Edu-Escape Room. Particularly, there were differences of 0.43, $0.47,0.48,0.94,1.73$ and 0.67 points in happiness, satisfaction, fun, nervousness, frustration and concern, respectively.

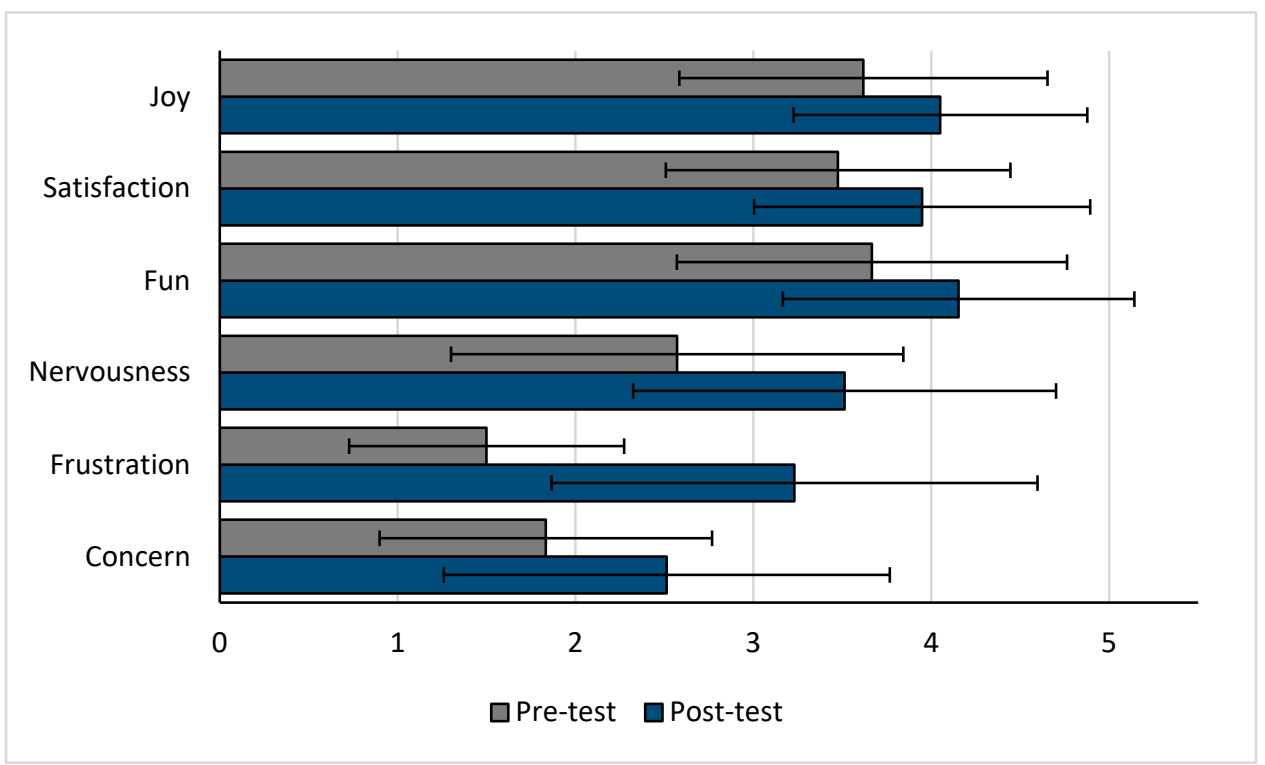

Figure 4. Comparison of means with significant differences of emotions before and after the intervention (pre- and post-test).

\subsection{Effect-Size (ES) and Principal Component Analysis (PCA) Analysis}

An ES analysis measures the strength of the relationship between variables in a statistical population or an estimate of that amount based on a sample. It can refer to the value of a statistic calculated from a sample of data, the value of a parameter in a hypothetical statistical population or the equation that operationalizes how statistics or parameters lead to the value of the ES [50]. Some studies [51,52] indicate that the ES estimation is useful for determining the practical or theoretical importance of an effect, the relative contributions of factors or the power of analysis. It also provides a way to evaluate the data more thoroughly and precisely. In this research, the estimate of the ES was used to measure the magnitude of the treatment effect [53].

Cohen's $d$ is defined as the difference between two means divided by a standard deviation for the data as shown in Equation (1) [53].

$$
d=\frac{\bar{x}_{1}-\bar{x}_{2}}{s}=\frac{\mu_{1}-\mu_{2}}{s}
$$

$S$ is the pooled standard deviation and is calculated using the following Equation (2) [53]:

$$
s=\sqrt{\frac{\left(n_{1}-1\right) S_{1}^{2}+\left(n_{2}-1\right) S_{2}^{2}}{n_{1}+n_{2}-2}}
$$

Depending on the values obtained for the calculation of Cohen's $d$, the ES of between $0.2-0.3$ could be considered "small", around 0.5-0.8 as a "medium" effect, and 0.8-1.0 as a 
"large" effect [53]. Later, Sawilowsky [54] added to these magnitudes of the effects "very small" when Cohen's $d$ is less than 0.1, "very large" when Cohen's $d$ is around 1.2 and "huge" when Cohen's $d$ is around 2 points.

In this study, we calculated the ES (see Table 4) of the variables that showed significant differences between the means before and after the intervention to measure the magnitude of the online-based Edu-Escape Room. These variables consisted of item 11 (Q11) "I like the challenges of scientific activities", the positive emotions "joy", "satisfaction", "fun" and the negative emotions "nervousness", "frustration", "concern".

Table 4. The Effect Size (ES) value (Cohen's $d$ ) of the intervention of variables with significant differences (Mann-Whitney test).

\begin{tabular}{cccc}
\hline & \multicolumn{3}{c}{ Effect Size (ES) } \\
\hline Variable & $\begin{array}{c}p \text {-Value } \\
\text { (Mann-Whitney } \\
\text { Test) }\end{array}$ & ES Value (Cohen's $d$ ) & ES \\
\hline Q11 & 0.031 & 0.5 & Medium \\
Joy & 0.047 & 0.5 & Medium \\
Satisfaction & 0.015 & 0.5 & Medium \\
Fun & 0.034 & 0.5 & Medium \\
Nervousness & 0.001 & 0.7 & Medium \\
Frustration & 0.000 & 1.6 & Large \\
Concern & 0.012 & 0.6 & Medium \\
\hline
\end{tabular}

As shown in Table 4, the online-based Edu-Escape Room had a medium effect on all variables with significant differences except for the variable "frustration", where it had a large effect.

The PCA was conducted with the aim to interpret all data collected. The PCA is a method used to describe a data set in terms of new correlated variables (components). The components were ordered by the amount of original variance, so the PCA is useful for reducing the dimensionality of a data set. This tool was useful to summarize large numbers of data and to determine how samples differed from each other (pre- and post-test data), which variables contribute more importantly to this difference and how variables correlated $[55,56]$. The PCA was done for the variables with statistically significant differences, i.e., Q11 item of attitudes and self-efficacy questionnaire, "I like the challenges of scientific activities" and the emotions "joy", "satisfaction", "fun" (positive emotions), "nervousness", "frustration", "concern". Other emotions analyzed "confidence", "enthusiasm", "uncertainty" and "boredom", which were aggregated as well but did not have much influence. Figures 5 and 6 show a PCA diagrams obtained from this analysis.

Figure 5 shows principal component 1 (PC1) and principal component 2 (PC2), which explain $62.9 \%$ and $13 \%$ of the total variance, respectively. PC1 (62.9\% of the variance) can group samples in two groups. One group belongs to positive emotions and is in the positive part of PC1, while negative emotions are assembled in a second group in the negative part of PC1. No sample grouping is observed along PC2.

Figure 6 shows principal component 1 (PC1) and principal component 2 (PC2), which explain $34.4 \%$ and $30.5 \%$ of the total variance, respectively. PC1 (34.4\% of the variance) can arrange the sample in two groups (pre- and post-test answers). Pre-test answers are located mainly in the negative part of $\mathrm{PC} 1$, while post-test answers are grouped in the positive part of PC1. No sample grouping is observed along PC2. Thus, PC1, which represents the effect of the instruction methodology in the emotions toward activity implemented of PSTs, can distinguish between the PSTs before and after the intervention, presenting more positive emotions after completing the activity. 


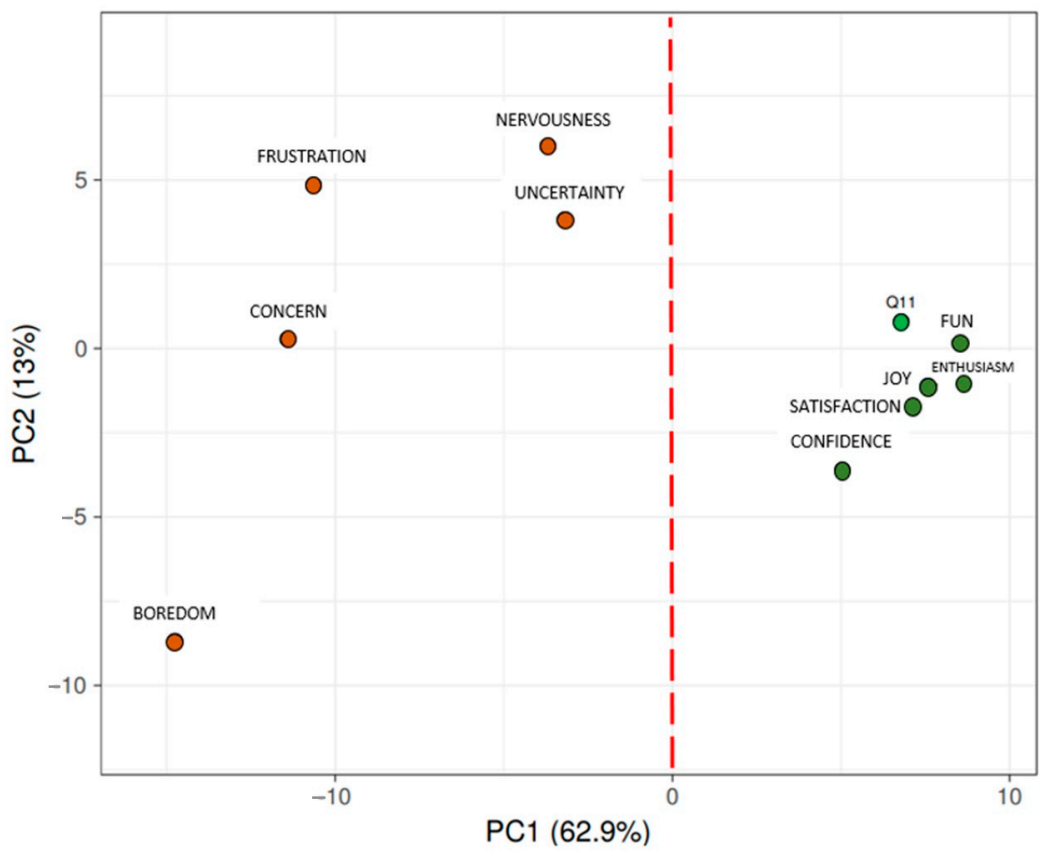

Figure 5. The principal component analysis (PCA) diagram, $\mathrm{X}$ and $\mathrm{Y}$ axis show principal component 1 and principal component 2 that explain $62.9 \%$ and $13 \%$ of the total variance, respectively. Green points are positive emotions, light green point is Q11 and orange points are negative emotions.

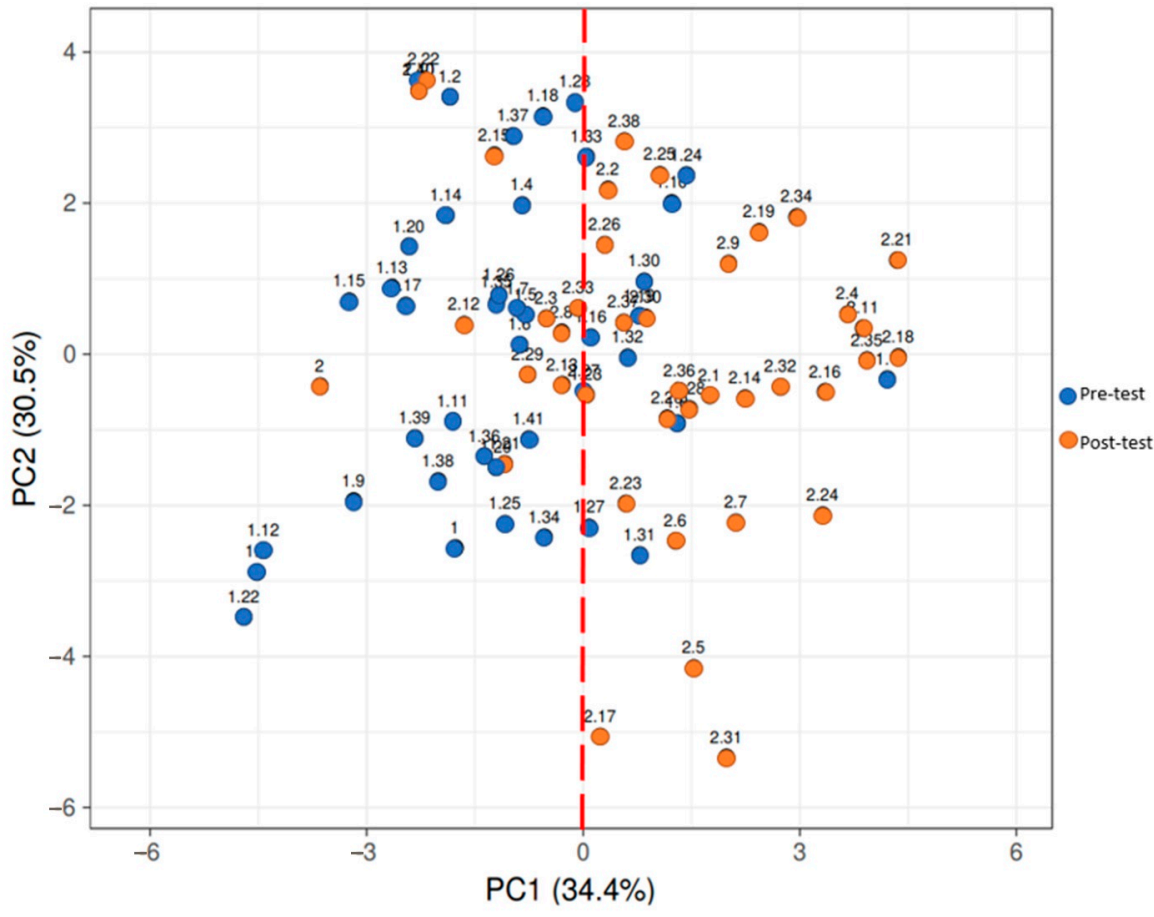

Figure 6. PCA diagram, $\mathrm{X}$ and $\mathrm{Y}$ axis show principal component 1 and principal component 2 that explain $36.1 \%$ and $31.5 \%$ of the total variance, respectively. Blue points are answers to pre-test and orange points are answers to post-test. The numbers associated with each point belong to each student's answer in pre-test (1) and post-test (2).

\subsection{SEM-PLS Data Analysis}

In order to get a better understanding of the influence of the instruction designed on the studied variables, an SEM-PLS analysis was carried out. The model was built grouping the variables into "positive emotions" (E_1 to E_5), negative emotions (E_6 to 
E_10), "self-efficacy believes" (AF_1 to AF_7) and "attitudes towards science" (ATT_1 to ATT_17). Based on the results, all positive emotions have a positive significant effect of self-efficacy beliefs ( $t$-value: $2.105, p=0.035$ ), while negative emotions showed a negative significant effect with self-efficacy ( $\mathrm{t}-\mathrm{value:} 2.697, p=0.007$ ). According to the designed model, we also observed that there was a strong significant effect between attitudes and self-efficacy towardss science (t-value: 18.017, $p=0.000$ ). Finally, the loads of each item were close to or greater than the recommended value $(>0.700)$. Considering such values, the reliability, and validity of the constructs can be granted [57]. Results are summarized in Figure 7.

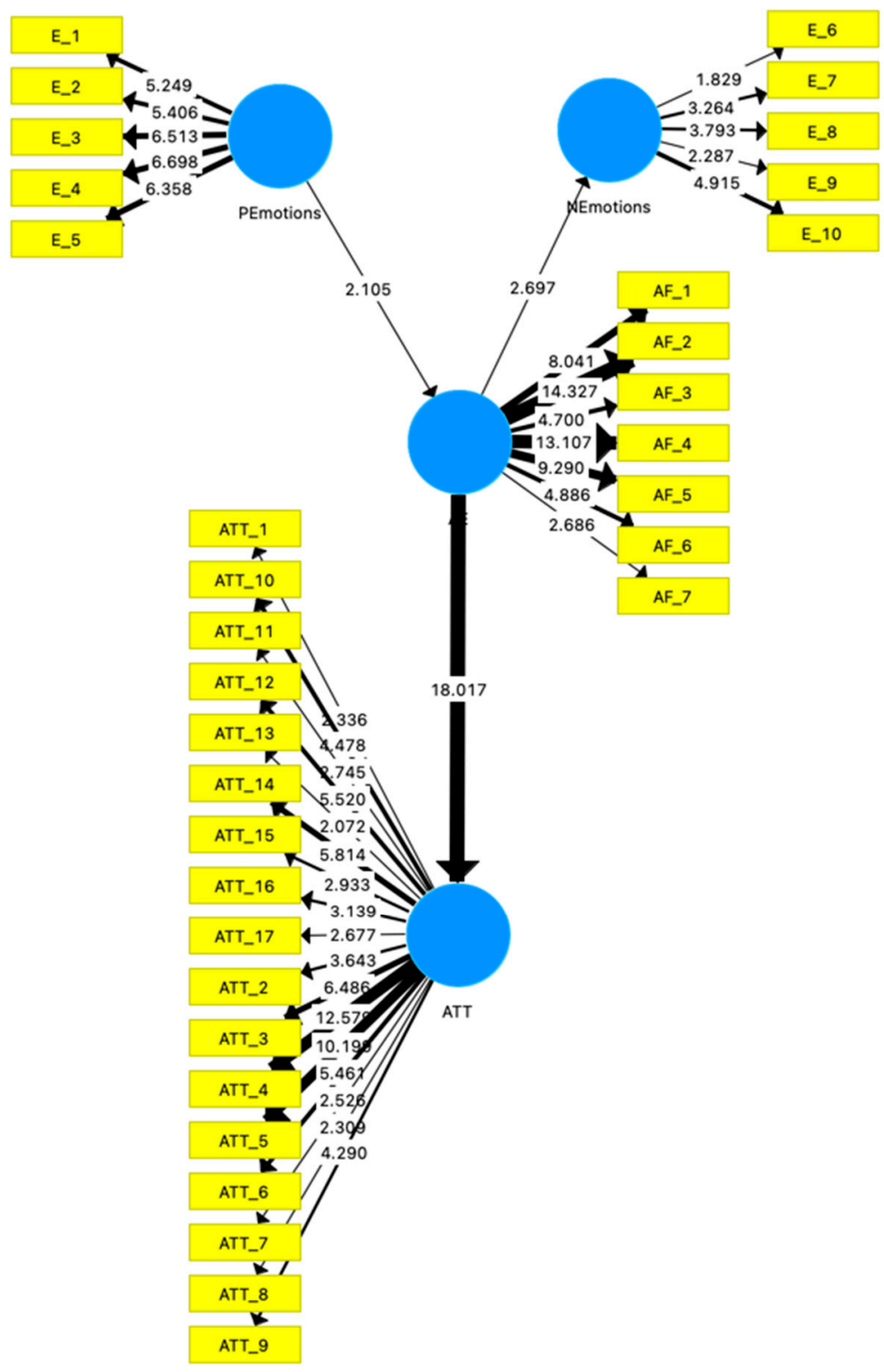

Figure 7. Results of the relation between the studied variables after applying the structural equation modeling partial least squares (SEM-PLS) analysis. t-values are shown for the inner and outer model. Paths have been highlighted based on relative values.

\subsection{Discussions}

Comparison of the results revealed significant differences about the multidimensional domain of the PSTs. Statistically significant differences were observed in the Q11 "I like the challenges of scientific activities" of the attitude and self-efficacy questionnaire, which showed an increase of more than 0.4 points compared to the pre-test. Maintaining 
positive attitudes and fostering high self-efficacy towards the online-based Edu-Escape Room of science was associated with higher performance and motivation in the contents covered $[58,59]$. Sequentially, an active teaching methodology such as a virtual Escape Room could lead to increased attitudes and self-efficacy of participants [14,30], which was especially useful in STEM courses.

The emotions analyzed showed statistically significant differences in 6 of 10 emotions analyzed: 3 positive emotions-joy, satisfaction and fun - and 3 negative emotionsnervousness, frustration and concern. All these emotions had an increase after the proposed activity. Concerning positive emotions, positive emotional states were encouraged while applying active instructional methodology such as an Escape Room game and flipped classroom $[2,27,29,39]$. This was especially important in STEM disciplines as students began to show a deficiency of interest in science at an early age, which might impact the adulthood and decreased the choice of STEM careers later in life $[30,60]$. The increase in negative emotions could be due to a multitude of factors. One of these was the pre-university background of PSTs; most of the sample (69\%) had studied Humanities or Social Sciences in High School. This component was associated with lower motivation and the presence of an unfavorable image and negative emotions towards science in general $[29,61]$. The difficulty of developing the proposed intervention in an online environment might be another factor. Online teaching had various disadvantages such as the feeling of isolation, excessive self-management or the absence of face-to-face interaction between instructors and students. Moreover, it could affect factors such as the student's capacity for independence, the difficulty of follow-up, coordination and communication, and the difficulty of the process in comparison with traditional teaching. This was essential in practical scientific activities that required synchronous follow-up like the proposed activity in this study $[59,62]$.

According to the ES analysis results, it was observed that the online-based Edu-Escape Room has a medium effect on all variables with significant differences except for the variable "frustration". This type of effect was within the acceptable range of ES, and there were some factors such as the heterogeneity of the sample that could decrease the effects of the intervention [63,64]. The online-based Edu-Escape Room had a large effect on the negative emotion "frustration". According to another research study [9,31], when doing an Escape Room, it was important to be aware that it was normal that some negative emotions might appear such as frustration or nervousness due to game components. Frustration might arise for a variety of reasons, such as the difficulty of a challenge, the time taken to solve it or the participant's lack of knowledge. According to some studies, the learning processes that generated knowledge were likely to produce emotions such as frustration, uncertainty, anxiety and boredom [65-67]. However, given the complexity of interactions between emotions and variables, emotions such as frustration, anxiety and shame were potential activating elements of the learning process [67].

Regarding the PCA, the variables were arranged into two groups: positive variables (Q11 and positive emotions) and negative variables (negative emotions). Concerning questionnaire answers, there were two groups: pre-test answers and post-test answers. It was observed that pre-test answers were located mainly in the negative part of the $\mathrm{x}$-axis as well as negative variables, and post-test answers were grouped in the positive part of $\mathrm{x}$-axis of the diagram as well as positive variables. Thus, it could students before and after the intervention could be distinguished. There was a positive correlation between the Q11 and positive emotions with the post-test, and there was a correlation between negative emotions and post-test. The results were consistent with other studies $[44,56,59]$. This information completed the results of the means comparison analysis and the ES analysis. The PCA results confirmed that there was a dependency correlation between the results of the Q11, positive emotions and post-test and between the results of the pre-test and negative emotions. Thus, the proposed online-based Edu-Escape Room could be effective for improving the multidimensional domain of PSTs.

Finally, the SEM-PLS analysis allowed us to determine the effects of the studied variables after applying the online-based Edu-Escape Room developed as an educative 
tool to teach STEM contents in the University course of the bachelor's degree in Primary Education. According to the results obtained, there PSTs' emotions played a significant effect on the PSTs' self-efficacy beliefs, and these beliefs also have a positive effect on their attitudes towards science.

\section{Conclusions}

The study analyses the effects of multidimensional domain of PSTs produced by an online-based Edu-Escape Room developed as an educative tool in the University course within the bachelor's degree in Primary Education at a Teacher Training College (Spain).

According to the results, there is an increase in positive attitudes and high self-efficacy items after the intervention. In particular, Q11, "I like the challenges of scientific activities", had a significant difference and its value increased considerably. Regarding the emotions analyzed, there were significant differences in three positive emotions, "joy", "satisfaction" and "fun" and three negative emotions, "nervousness", "frustration" and "concern". Specifically, there was an increase in these emotions after implementing the online-based Edu-Escape Room. Here, positive emotions were generated due to Escape Room games used as an educative tool, which promoted motivation, interest and fun. Negative emotions were mostly generated because of the difficulties of an online environment. The online-based Edu-Escape Room had a medium effect for items with significant differences except for the emotion "frustration", where the activity had a large effect. Here, negative emotions such as frustration were frequently viewed as detrimental to motivation and learning, but they were also interpreted under some circumstances as beneficial in a learning process. It was also observed that there was a correlation between some items of attitudes, self-efficacy and positive emotions and the post-test, which indicated that there were benefits in the multidimensional domain of the PSTs after having implemented the online-based Edu-Escape Room. Thus, this finding was supported by the SEM-PLS analysis, which showed the tool's effect that the PSTs' emotions influenced to a significant effect of the positive self-efficacy and attitudes towards science. Hence, this tool could be utilized in future works by adding improvements to achieve better results and greater benefits in the multidimensional domain of PSTs.

Author Contributions: Conceptualization, F.Y.-P., J.S.J. and D.G.-G.; methodology F.Y.-P., J.S.J. and D.G.-G.; software, F.Y.-P., J.S.J. and D.G.-G.; validation, F.Y.-P., J.S.J. and D.G.-G.; formal analysis, F.Y.-P., J.S.J. and D.G.-G.; investigation, F.Y.-P., J.S.J. and D.G.-G.; resources, F.Y.-P., J.S.J. and D.G.-G.; data curation, F.Y.-P., J.S.J. and D.G.-G.; writing—original draft preparation, F.Y.-P., J.S.J. and D.G.-G.; writing-review and editing, F.Y.-P., J.S.J. and D.G.-G.; visualization, F.Y.-P., J.S.J. and D.G.-G.; supervision, J.S.J. and D.G.-G.; project administration, J.S.J. and D.G.-G. All authors have read and agreed to the published version of the manuscript.

Funding: The authors gratefully acknowledge the Consejerería de Economía, Ciencia y Agenda Digital de la Junta de Extremadura y Fondo Europeo de Desarrollo Regional (FEDER)—Project IB18004, which support this research possible.

Institutional Review Board Statement: The study was conducted according to the guidelines of the Declaration of Helsinki, and approved by Ethics Committee of University of Extremadura (ref. 94/2018).

Informed Consent Statement: Not applicable.

Data Availability Statement: Data available on request.

Conflicts of Interest: The authors declare no conflict of interest.

\section{References}

1. Legaki, N.Z.; Xi, N.; Karpouzis, K.; Assimakopoulos, V. The effect of challenge-based gamification on learning: An experiment in the context of statistics education. Int. J. Hum. Comput. Stud. 2020, 144, 102496. [CrossRef] [PubMed]

2. Nicholson, S. Peeking Behind the Locked Door: A Survey of Escape Room Facilities. White Paper. 2015. Available online: http:/ / scottnicholson.com/pubs/erfacwhite.pdf (accessed on 22 November 2020). 
3. Vázquez, A.; Manassero, M.A. Juegos para enseñar la naturaleza del conocimiento científico y tecnológico. Educar 2017, 53, 149-170. [CrossRef]

4. Deterding, S.; Dixon, D.; Khaled, R.; Nacke, L. From game design elements to gamefulness: Defining "gamification. In Proceedings of the 15th International Academic MindTrek Conference: Envisioning Future Media Environments, Tampere, Finland, 29-30 September 2011; pp. 9-15.

5. González, C.S. Estrategias para trabajar la creatividad en la Educación Superior: Pensamiento de diseño, aprendizaje basado en juegos y en proyectos. RED 2014, 40,1-15.

6. Su, C.H. The Effect of Users' Behavioral intention on gamification augmented reality in STEM (GAR-STEM) education. J. Balt. Sci. Educ. 2019, 18, 450. [CrossRef]

7. Zamora-Polo, F.; Corrales-Serrano, M.; Sánchez-Martín, J.; Espejo-Antúnez, L. Nonscientific University Students Training in General Science Using an Active-Learning Merged Pedagogy: Gamification in a Flipped Classroom. Educ. Sci. 2019, 9, 297. [CrossRef]

8. Pérez-Vázquez, E.; Gilabert-Cerdá, A.; Lledó-Carreres, A. Gamificación en la educación universitaria: El uso del escape room como estrategia de aprendizaje. In Investigación e innovación en la Enseñanza Superior: Nuevos Contextos, Nuevas Ideas; Octaedro: Barcelona, Spain, 2019; pp. 660-668.

9. Sierra, M.C.; Fernández-Sánchez, M.R. Gamificando el aula universitaria. Análisis de una experiencia de Escape Room en educación superior. REXE 2019, 18, 105-115. [CrossRef]

10. Nicholson, S. Creating engaging escape rooms for the classroom. Child. Educ. 2018, 94, 44-49. [CrossRef]

11. Borrego, C.; Fernández, C.; Blanes, I.; Robles, S. Room escape at class: Escape games activities to facilitate the motivation and learning in computer science. JOTSE 2017, 7, 162-171. [CrossRef]

12. Gómez-Urquiza, J.L.; Gómez-Salgado, J.; Albendín-García, L.; Correa-Rodríguez, M.; González-Jiménez, E.; Cañadas-De la Fuente, G.A. The impact on nursing students' opinions and motivation of using a "Nursing Escape Room" as a teaching game: A descriptive study. Nurse Educ. Today 2019, 72, 73-76. [CrossRef]

13. Brown, N.; Darby, W.; Coronel, H. An escape room as a simulation teaching strategy. Clin. Simul. Nurs. 2019, 30, 1-6. [CrossRef]

14. Sánchez-Martín, J.; Corrales-Serrano, M.; Luque-Sendra, A.; Zamora-Polo, F. Exit for success. Gamifying science and technology for university students using escape-room. A preliminary approach. Heliyon 2020, 6, 04340. [CrossRef] [PubMed]

15. Miller, K.; Sonnert, G.; Sadler, P. The influence of students' participation in STEM competitions on their interest in STEM careers. Int. J. Sci. Educ. 2018, 8, 95-114. [CrossRef]

16. González-Gómez, D.; Airado Rodríguez, D.; Cañada-Cañada, F.; Jeong, J.S. A comprehensive application to assist in acid-base titration self-learning: An approach for high school and undergraduate students. J. Chem. Educ. 2015, 5, 855-863. [CrossRef]

17. UNESCO. UN Decade of Education for Sustainable Development, 2005-2014: The DESD at a Glance; UNESDOC: New York, NY, USA, 2005.

18. Pavlova, M. Teaching and learning for sustainable development: ESD research in technology education. Int. J. Technol. Des. Educ. 2013, 23, 733-748. [CrossRef]

19. UNESCO. UNESCO Moving Forward the 2030 Agenda for Sustainable Development; UNESDOC: New York, NY, USA, 2017.

20. Sterling, S. Sustainable Education: Re-Visioning Learning and Change. Schumacher Briefings; ERIC: Bristol, UK, 2001.

21. Jeong, J.S.; González-Gómez, D. A web-based tool framing a collective method for optimizing the location of a renewable energy facility and its possible application to sustainable STEM education. J. Clean. Prod. 2020, 251, 119747. [CrossRef]

22. Wiswall, M.; Stiefel, L.; Schwartz, A.E.; Boccardo, J. Does attending a STEM high school improve student performance? Evidence from New York City. Econ. Educ. Rev. 2014, 40, 93-105. [CrossRef]

23. Osborne, J.; Dillon, J. Science Education in Europe: Critical Reflections; The Nuffield Foundation: London, UK, 2008.

24. Vázquez, A.; Manassero, M.A. El descenso de las actitudes hacia la ciencia de chicos y chicas en la educación obligatoria. Ciênc. Educ. 2011, 17, 249-268. [CrossRef]

25. Tai, R.; Liu, C.; Maltese, A.; Fan, X. Planning early for careers in science. Science 2006, 312, 1143-1144. [CrossRef]

26. Garritz, A. Personal Reflection: Pedagogical Content Knowledge and the Affective domain of Scholarship of Teaching and Learning. IJSOTL 2010, 4, 26. [CrossRef]

27. Itzek-Greulich, H.; Vollmer, C. Emotional and motivational outcomes of lab work in the secondary intermediate track: The contribution of a science center outreach lab. J. Res. Sci. Teach. 2017, 54, 3-28. [CrossRef]

28. Koballa, T.R.; Bradbury, L.U.; Glynn, S.M.; Deaton, C.M. Conceptions of science teacher mentoring and mentoring practice in an alternative certification program. J. Sci. Teach. Educ. 2008, 19, 391-411. [CrossRef]

29. Pekrun, R.; Muis, K.R.; Frenzel, A.C.; Goetz, T. Emotions at School; Routledge: New York, NY, USA, 2017.

30. Vázquez, A.; Manassero, M.A. En defensa de las actitudes y emociones en la educación científica (I): Evidencias y argumentos generales (In defense of attitudes and emotions in science education (I): General arguments and evidence). REurEDC 2007, 4, 247-271.

31. Clauson, A.; Hahn, L.; Frame, T.; Hagan, A.; Bynum, L.A.; Thompson, M.E.; Kiningham, K. An innovative escape room activity to assess student readiness for advanced pharmacy practice experiences (APPEs). Curr. Pharm. Teach. Learn. 2019, 11, 723-728. [CrossRef] [PubMed]

32. Schlegel, R.J.; Chu, S.L.; Chen, K.; Deuermeyer, E.; Christy, A.G.; Quek, F. Making in the classroom: Longitudinal evidence of increases in self-efficacy and STEM possible selves over time. Comput. Educ. 2019, 142, 103637. [CrossRef] 
33. Bandura, A. Self-efficacy. Corsini Encycl. Psychol. 2010, 1-3. [CrossRef]

34. Katsantonis, I.G. Investigation of the Impact of School Climate and Teachers' Self-Efficacy on Job Satisfaction: A Cross-Cultural Approach. Eur. J. Investig. Health Psychol. Educ. 2020, 10, 119-133. [CrossRef]

35. Namaziandost, E.; Çakmak, F. An account of EFL learners' self-efficacy and gender in the Flipped Classroom Model. Educ. Inf. Technol. 2020, 25, 4041-4055. [CrossRef]

36. Kazempour, M.S. I can't teach science! A case study of an elementary pre-service teacher's intersection of science experiences, beliefs, attitude, and self-efficacy. Int. J. Environ. Sci. Educ. 2014, 9, 77-96.

37. Kurniawan, D.A.; Astalini, A.; Darmaji, D.; Melsayanti, R. Students' Attitude towards Natural Sciences. Int. J. Eval. Res. Educ. 2019, 8, 455-460. [CrossRef]

38. Fernández-Cézar, R.; Garrido, D.; Solano-Pinto, N. Do Science, Technology, Engineering and Mathematics (STEM) experimentation outreach programs affect attitudes towards mathematics and science? A quasi-experiment in primary education. Mathematics 2020, 8, 1490. [CrossRef]

39. Jeong, J.S.; González-Gómez, D.; Cañada-Cañada, F. How does a flipped classroom course affect the affective domain toward science course? Interact. Learn. Environ. 2019, 1-13. [CrossRef]

40. Schruba, A.E. Evaluation of Student Attitude toward Science and Self-Efficacy in a Non-Majors College Biology Course; Texas Christian University: Fort Worth, TX, USA, 2008.

41. Jeong, J.S.; González-Gómez, D.; Conde-Núñez, C.; Gallego-Picó, A. Examination of students' engagement with R-SPQ-2F of learning approach in flipped sustainable science course. J. Balt. Sci. Educ. 2019, 18, 880-891. [CrossRef]

42. Bleicher, R.E. Revisiting the STEBI-B: Measuring self-efficacy in preservice elementary teachers. School Sci. Math. 2004, 104, 383-391. [CrossRef]

43. González-Gómez, D.; Jeong, J.S. Examining the Effect of an Online Formative Assessment Tool (OFAT) of Students' Motivation and Achievement for a University Science Education. J. Balt. Sci. Educ. 2020, 19, 401-414. [CrossRef]

44. Jeong, J.S.; González-Gómez, D.; Yllana-Prieto, F. Sustainable and Flipped STEM Education: Formative Assessment Online Interface for Observing Pre-Service Teachers' Performance and Motivation. Educ. Sci. 2020, 10, 283. [CrossRef]

45. Dunbar, R.L.; Dingel, M.J.; Dame, L.F.; Winchip, J.; Petzold, A.L. Student social self-efficacy, leadership status, and academic performance in collaborative learning environments. Stud. High. Educ. 2016, 38, 1507-1523. [CrossRef]

46. Harmon-Jones, C.; Bastian, B.; Harmon-Jones, E. The discrete emotions questionnaire: A new tool for measuring state self-reported emotions. PLoS ONE 2016, 11, e0159915. [CrossRef]

47. Bisquerra, R. Emotional Education and Well-Being; Praxis: Barcelona, Spain, 2005.

48. Etxeberria, J.; Tejedor, F.J. Descriptive data analysis in education. La Muralla Madrid 2005, 11, 1-12.

49. Jeong, J.S.; González-Gómez, D.; Cañada-Cañada, F. Students' Perceptions and Emotions toward Learning in a Flipped General Science Classroom. J. Sci. Educ. Technol. 2016, 25, 747-758. [CrossRef]

50. Kelley, K.; Preacher, K.J. On effect size. Psychol. Methods 2012, 17, 137-152. [CrossRef]

51. Rhea, M.R. Determining the magnitude of treatment effects in strength training research through the use of the effect size. $J$. Strength Cond. Res. 2004, 18, 918-920. [PubMed]

52. Fritz, C.O.; Morris, P.E.; Richler, J.J. Effect size estimates: Current use, calculations, and interpretation. J. Exp. Psychol. Gen. 2012, 141, 2-18. [CrossRef] [PubMed]

53. Cohen, J. Statistical Power Analysis for the Behavioral Sciences (2. Auflage); Erlbaum: Hillsdale, NJ, USA, 1988.

54. Jeong, J.S.; González-Gómez, D. Adapting to PSTs' pedagogical changes in sustainable mathematics education through flipped E-Learning: Ranking its criteria with MCDA/F-DEMATEL. Mathematics 2020, 8, 858. [CrossRef]

55. Peres-Neto, P.R.; Jackson, D.A.; Somers, K.M. How many principal components? Stopping rules for determining the number of non-trivial axes revisited. Comput. Stat. Data Anal. 2005, 49, 974-997. [CrossRef]

56. González-Gómez, D.; Jeong, J.S.; Cañada-Cañada, F. Enhancing science self-efficacy and attitudes of Pre-Service Teachers (PST) through a flipped classroom learning environment. Interact. Learn. Environ. 2019, 1-12. [CrossRef]

57. Arango-Morales, A.J.; Delgado-Cruz, A.; Tamayo-Salcedo, A.L. Digital Competence of Tourism Students: Explanatory Power of Professional Training. Eur. J. Investig. Health Psychol. Educ. 2020, 10, 310-326. [CrossRef]

58. Brown, S.D.; Tramayne, S.; Hoxha, D.; Telander, K.; Fan, X.; Lent, R.W. Social cognitive predictors of college students' academic performance and persistence: A meta-analytic path analysis. J. Vocat. Behav. 2008, 72, 298-308. [CrossRef]

59. Jeong, J.S.; González-Gómez, D.; Gallego-Picó, A.; Bravo, J.C. Effects of active learning methodologies on the students' emotions, self-efficacy beliefs and learning outcomes in a science distance learning course. JOTSE 2019, 9, 217-227. [CrossRef]

60. Van Aalderen-Smeets, S.I.; Van der Molen, J.H.W. Improving primary teacher' attitudes toward science by attitude-focused professional development. J. Res. Sci. Teach. 2015, 52, 710-734. [CrossRef]

61. González-Gómez, D.; Jeong, J.S.; Gallego, A.; Cañada-Cañada, F. Influencia de la metodología flipped en las emociones sentidas por estudiantes del Grado de Educación Primaria en clases de ciencias dependiendo del bachillerato cursado. Educ. Química 2018, $29,77-88$.

62. Arkorful, V.; Abaidoo, N. The role of e-learning, advantages and disadvantages of its adoption in higher education. Int. J. Instr. Technol. Distance Learn. 2015, 12, 29-42.

63. Cobley, S.; Baker, J.; Wattie, N.; McKenna, J. Annual age-grouping and athlete development: A meta-analytical review of relative age effects in sport. Sports Med. 2009, 39, 235-256. [CrossRef] [PubMed] 
64. Navarro, J.J.; García-Rubio, J.; Olivares, P.R. The Relative Age Effect and its Influence on Academic Performance. PLoS ONE 2015, 10, e0141895. [CrossRef] [PubMed]

65. Muis, K.R.; Pekrun, R.; Sinatra, G.M.; Azevedo, R.; Trevors, G.; Meier, E.; Heddy, B.C. The curious case of climate change: Testing a theoretical model of epistemic beliefs, epistemic emotions, and complex learning. Learn. Instr. 2015, 39, 168-183. [CrossRef]

66. Carruthers, P. Are epistemic emotions metacognitive? Philos. Psychol. 2017, 30, 58-78. [CrossRef]

67. Rowe, A.D.; Fitness, J. Understanding the role of negative emotions in adult learning and achievement: A social functional perspective. Behav. Sci. 2018, 8, 27. [CrossRef] 